\title{
Clinical profile and visual outcome of traumatic paediatric cataract in suburban Malaysia: a ten-year experience
}

Abdul-Rahim Adlina ${ }^{1}$, MD, Mmed, Ying-Jiun Chong $^{1}$, MD, Ismail Shatriah ${ }^{1}$, MD, MMed

INTRODUCTION Available data on traumatic cataract in Asian children is primarily confined to South Asian countries. We aimed to describe the demographics, nature of injury and visual outcomes of Malaysian children with traumatic cataract from a suburban area, and discuss the literature on Asian children with this condition.

METHODS We conducted a retrospective study of 29 children below 17 years of age who were diagnosed with traumatic paediatric cataract and who attended Hospital Universiti Sains Malaysia, Kelantan, Malaysia, between January 2000 and December 2010. Follow-up periods ranged from 12 to 120 months. Demographic data, clinical features, mechanism and extent of injury, and final visual outcome were recorded.

RESULTS The study population was predominantly male. The right eye was injured in $62.07 \%$ of patients. A majority of patients had penetrating injuries, with the most common cause being injury by an organic foreign body (24.14\%). Presenting visual acuity worse than $6 / 60$ was observed in $68.97 \%$ of patients. Only $34.48 \%$ of patients had a final corrected visual acuity of $6 / 12$ and better. $55.18 \%$ of patients were operated on within less than one month of their injuries. A majority of children sustained concurrent injuries to the anterior segment structures. Corneal opacity and amblyopia were the most common causes of poor final visual acuity.

CONCLUSION Health education and awareness are essential tools that can prevent avoidable blindness due to traumatic cataract in the paediatric population. The importance of rehabilitation programmes for these patients should be emphasised.

Keywords: Malaysian children, suburban area, traumatic paediatric cataract

\section{INTRODUCTION}

Traumatic cataract causes significant blindness in paediatric populations, particularly in developing countries. ${ }^{(1-3)}$ Concurrent morbidities such as endophthalmitis, retinal detachment, traumatic optic neuropathy and ruptured globe result in devastating visual loss in children with traumatic cataract.

Numerous studies on traumatic paediatric cataract have been published from Asian countries such as India, ${ }^{(4-14)}$ Pakistan, ${ }^{(15,16)}$ Nepal(17-19) and Korea. ${ }^{(20)}$ However, a PubMed database search of published literature on traumatic paediatric cataracts from developing countries in the Southeast Asian region revealed that no such data is available. The present study was designed to address this shortfall in current knowledge. We aimed to describe the demographics, nature of injury and visual outcomes among paediatric patients with traumatic cataract in a suburban area of Peninsular Malaysia, and discuss the relevant literature on traumatic paediatric cataract among Asian children.

\section{METHODS}

We conducted a retrospective cross-sectional review of 29 Malay children (aged less than 17 years) with ocular trauma who underwent lens surgery at Hospital Universiti Sains Malaysia (HUSM), Kubang Kerian, Kelantan, Malaysia, between January
2000 and December 2010, and were followed up for a minimum period of one year. The study was conducted in accordance with the Declaration of Helsinki, and the study protocol was approved by the Research and Ethical Committee of the School of Medical Sciences, Universiti Sains Malaysia. HUSM is a teaching hospital in the state of Kelantan, which is located in the northeastern part of Peninsular Malaysia, approximately $750 \mathrm{~km}$ off Kuala Lumpur, the capital of the country. A majority of the population of Kelantan is ethnically Malay, and agriculture remains the main activity within its local population.

All paediatric patients with traumatic cataract who required lens surgery at HUSM were identified and included in our study. The exclusion criteria were as follows: (a) pre-existing ocular disease such as amblyopia, refractive error, corneal opacity, allergic conjunctivitis, congenital optic atrophy or glaucoma; (b) history of ocular surgery; and (c) presence of systemic disease such as Down syndrome, Marfan syndrome and cerebral palsy.

The following data was documented and analysed: age; gender; laterality and mechanism of injury; presenting and final visual acuities; extent of injury; interval between injury and surgical intervention; and possible causes of poor final visual acuity. Consulting paediatric ophthalmologists were required to complete the Traumatic Paediatric Cataract Registry Forms.

${ }^{1}$ Department of Ophthalmology, School of Medical Sciences, Universiti Sains Malaysia, Kelantan, Malaysia

Correspondence: A/Prof Shatriah Ismail, Senior Lecturer and Consultant Paediatric Ophthalmologist, Department of Ophthalmology, School of Medical Sciences, Universiti Sains Malaysia, Kubang Kerian 16150, Kelantan, Malaysia. shatriah@kck.usm.my 
Table I. Demographics and injury characteristics of paediatric patients with traumatic cataract $(n=29)$.

\begin{tabular}{lc}
\hline Characteristic & No. (\%) \\
\hline Age range (yrs) & $5(17.24)$ \\
$1-6$ & $11(37.93)$ \\
$7-12$ & $13(44.83)$ \\
$13-17$ & \\
Gender & $24(82.76)$ \\
Boys & $5(17.24)$ \\
Girls & \\
Laterality & $18(62.07)$ \\
Right eye & $11(37.93)$ \\
Left eye & \\
Mechanism of injury & $11(37.93)$ \\
Blunt trauma & $18(62.07)$ \\
Penetrating injury & \\
Cause of injury & $3(10.34)$ \\
Fall & $2(6.90)$ \\
Animal attack & $7(24.14)$ \\
Organic foreign body & $3(10.34)$ \\
Metal foreign body & $2(6.90)$ \\
Motor vehicle accident & $2(6.90)$ \\
Toys & $3(10.34)$ \\
Fishing tools & $1(3.44)$ \\
Sports & $2(6.90)$ \\
Stationery items & $4(13.80)$ \\
\hline Other/unknown &
\end{tabular}

Table II. Clinical characteristics of paediatric patients with traumatic cataract $(n=29)$.

\begin{tabular}{lc}
\hline Characteristic & No. (\%) \\
\hline Visual acuity at presentation & $0(0.00)$ \\
$6 / 12$ and better & $9(31.03)$ \\
$6 / 15-6 / 60$ & $20(68.97)$ \\
Worse than 6/60 & \\
Final visual acuity & $10(34.48)$ \\
$6 / 12$ and better & $12(41.38)$ \\
$6 / 15-6 / 60$ & $7(24.14)$ \\
Worse than 6/60 & \\
Time to lens surgery after injury (mths) & $16(55.18)$ \\
$<1$ & $5(17.24)$ \\
$1-6$ & $3(10.34)$ \\
$>6$ & $5(17.24)$ \\
Missing data & \\
Cause of visual impairment* & $10(52.63)$ \\
Corneal opacity & $5(26.32)$ \\
Amblyopia & $2(10.53)$ \\
Secondary glaucoma & $1(5.26)$ \\
Macular scarring & $1(5.26)$ \\
Traumatic optic neuropathy &
\end{tabular}

Data was analysed using the Statistical Package for the Social Sciences for Windows version 18.0 (SPSS Inc, Chicago, IL, USA).

\section{RESULTS}

Table I presents the demographics and injury characteristics of our patient population. A total of 29 patients (29 eyes) with traumatic paediatric cataract were recruited according to the study protocol. A majority of the patients $(82.76 \%, 24$ eyes) were boys, and the age range of the cohort was 3-17 years (Table I). The right eye was more frequently injured compared to the left eye (62.07\% vs. $37.93 \%)$, and 18 (62.07\%) eyes had penetrating injuries. Eye injuries resulting from organic foreign bodies were
Table III. Structural injuries among paediatric patients with traumatic cataract $(n=29)$.

\begin{tabular}{ll}
\hline Characteristic & No. (\%) \\
\hline $\begin{array}{l}\text { Single } \\
\text { Lens only }\end{array}$ & $0(0.00)$ \\
Multiple & \\
Lens and cornea & $7(24.14)$ \\
Lens and iris & $1(3.44)$ \\
Lens and anterior chamber & $2(6.90)$ \\
Lens, cornea and iris & $4(13.80)$ \\
Lens, cornea and anterior chamber & $6(20.72)$ \\
Lens, iris and anterior chamber & $3(10.34)$ \\
Lens, cornea, iris and anterior chamber & $1(3.44)$ \\
Lens, cornea, anterior chamber and macula & $2(6.90)$ \\
Lens, cornea, anterior chamber and vitreous & $1(3.44)$ \\
Lens, iris, macula and retina & $1(3.44)$ \\
Lens, cornea, retina and optic nerve & $1(3.44)$ \\
\hline
\end{tabular}

the most common (7 eyes, 24.14\%), followed by falls ( 3 eyes, $10.34 \%$ ), metal foreign bodies ( 3 eyes, $10.34 \%$ ) and fishing tool injuries (3 eyes, 10.34\%). Unknown causes of injury were noted in $4(13.80 \%)$ eyes in children aged less than five years.

Table II shows the clinical characteristics of children with traumatic cataract. 20 eyes $(68.97 \%)$ had a presenting visual acuity worse than 6/60. More than half of the patients (16 eyes, 55.18\%) required cataract surgery and intraocular lens implantation during the first month following injury. Final corrected visual acuity of $6 / 12$ and better was observed in only $34.48 \%$ (10 eyes) of patients. Visual impairment due to corneal opacity $(52.63 \%)$, amblyopia $(26.32 \%)$, secondary glaucoma $(10.53 \%)$, macular scarring $(5.26 \%)$ and traumatic optic neuropathy $(5.26 \%)$ was noted in the remaining patients.

Table III shows the extent of tissue injury according to the anatomical structures affected in our patients. A majority of injuries (24 eyes, $82.78 \%$ ) were confined to the anterior segment structures and lens. Injuries among the remaining patients involved both the anterior and posterior segments.

\section{DISCUSSION}

Paediatric eye injury causes significant morbidity in addition to economic burden and psychological stress in developing countries such as Malaysia. Such injuries continue to occur despite numerous health awareness and education campaigns. The present study, which aimed to determine the demographics, nature of injury and visual outcomes in suburban Malaysian children with traumatic cataract, was conducted in an area where agriculture is the main economic activity. Table IV provides a comparative analysis of the demographic data, cause of injury and final visual acuity between the present study and the published literature on traumatic paediatric cataract from Asian countries. ${ }^{(6,9,12,15,17,20)}$

Our retrospective analysis showed that traumatic cataract occurred predominantly in boys. This finding was consistent

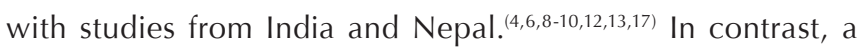
Korean study reported more girls (five eyes from three girls and two boys) who underwent scleral fixation of intraocular lens implants following traumatic paediatric cataract, ${ }^{(20)}$ while Cheema 
Table IV. Comparison of selected studies on traumatic cataract among Asian children.

\begin{tabular}{|c|c|c|c|c|c|c|c|}
\hline \multirow[t]{2}{*}{ Variable } & \multicolumn{7}{|c|}{ No. (\%) } \\
\hline & $\begin{array}{l}\text { Eckstein } \\
\text { et } \text { al }^{(12)}\end{array}$ & $\begin{array}{l}\text { Cheema } \\
\text { et } \mathrm{al}^{(15)}\end{array}$ & $\begin{array}{l}\text { Kamlesh } \\
\text { et } \mathrm{al}^{(9)}\end{array}$ & $\begin{array}{l}\text { Kumar } \\
\text { et } \mathrm{al}^{(17)}\end{array}$ & $\begin{array}{l}\text { Hyun et } \\
\mathrm{al}^{(20)}\end{array}$ & $\begin{array}{l}\text { Ram } \\
\text { et } \mathrm{al}^{(6)}\end{array}$ & Present study \\
\hline Country/year & $\begin{array}{c}\text { India/ } \\
1998\end{array}$ & $\begin{array}{l}\text { Pakistan/ } \\
1999\end{array}$ & $\begin{array}{l}\text { India/ } \\
2004\end{array}$ & $\begin{array}{l}\text { Nepal/ } \\
2008\end{array}$ & $\begin{array}{c}\text { Korea/ } \\
2009\end{array}$ & $\begin{array}{l}\text { India/ } \\
2012\end{array}$ & $\begin{array}{l}\text { Malaysia/ } \\
2014\end{array}$ \\
\hline \multicolumn{8}{|l|}{ Gender } \\
\hline Girls & $11(21.2)$ & $8(50.0)$ & $8(26.7)$ & $39(34.2)$ & $3(60.0)$ & $15(15.0)$ & $5(17.24)$ \\
\hline Boys & $41(78.8)$ & $8(50.0)$ & $22(73.3)$ & $75(65.8)$ & $2(40.0)$ & $85(85.0)$ & $24(82.76)$ \\
\hline Age at onset* (yrs) & $7.20(2-10)$ & $5.67(3.6-9.0)$ & $7.00(2-12)$ & $6.64(3-10)$ & NA & $8.05(1-15)$ & $10.67(1-17)$ \\
\hline Injured eyes & $52(100)$ & $16(100)$ & $30(100)$ & $114(100)$ & $5(100)$ & $100(100)$ & $29(100)$ \\
\hline \multicolumn{8}{|l|}{ Laterality } \\
\hline Unilateral & $52(100)$ & NA & $30(100)$ & NA & $5(100)$ & $100(100)$ & $29(100)$ \\
\hline Right eye & NA & NA & NA & NA & $2(40.0)$ & NA & $18(62.07)$ \\
\hline Left eye & NA & NA & NA & NA & $3(60.0)$ & NA & $11(37.93)$ \\
\hline Bilateral & $0(0)$ & NA & $0(0)$ & NA & $0(0)$ & $0(0)$ & $0(0)$ \\
\hline \multicolumn{8}{|l|}{ Mechanism of injury } \\
\hline Penetrating & NA & $10(62.5)$ & NA & $114(100)$ & NA & $65(65.0)$ & $18(62.07)$ \\
\hline Blunt & NA & $6(37.5)$ & NA & $0(0)$ & NA & $35(35.0)$ & $11(37.93)$ \\
\hline \multicolumn{8}{|l|}{ Cause of injury } \\
\hline Fall & NA & $0(0)$ & $0(0)$ & NA & NA & NA & $3(10.34)$ \\
\hline Animal attack & NA & $0(0)$ & $0(0)$ & NA & NA & NA & $2(6.90)$ \\
\hline Toys & NA & $0(0)$ & $0(0)$ & NA & NA & NA & $2(6.90)$ \\
\hline Sports & NA & $1(6.2)$ & $14(46.7)$ & NA & NA & NA & $1(3.44)$ \\
\hline Stationery items & NA & $1(6.2)$ & $0(0)$ & NA & NA & NA & $2(6.90)$ \\
\hline Other & NA & $14(87.6)$ & $16(53.3)$ & NA & NA & NA & $19(65.52)$ \\
\hline \multicolumn{8}{|l|}{$\begin{array}{l}\text { Visual acuity at } \\
\text { presentation }^{+}\end{array}$} \\
\hline $6 / 12$ and better & $0(0)$ & NA & NA & NA & $2(40.0)$ & NA & $0(0)$ \\
\hline $6 / 60$ and worse & $46(88.0)$ & NA & NA & NA & $0(0)$ & NA & $20(68.97)$ \\
\hline \multicolumn{8}{|l|}{ Final visual acuity ${ }^{+}$} \\
\hline \multicolumn{8}{|l|}{ Extent of injury } \\
\hline Lens only & NA & $6(37.5)$ & NA & $0(0)$ & $1(20.0)$ & NA & $0(0.00)$ \\
\hline $\begin{array}{l}\text { Lens and anterior } \\
\text { segment structures }\end{array}$ & NA & $10(62.5)$ & 6 eyes & NA & $2(40.0)$ & NA & $24(82.78)$ \\
\hline $\begin{array}{l}\text { Lens and posterior } \\
\text { segment structures }\end{array}$ & $3(5.8)$ & $0(0)$ & 30 eyes & NA & $0(0)$ & NA & $0(0.00)$ \\
\hline $\begin{array}{l}\text { Lens, anterior and } \\
\text { posterior segments } \\
\text { structures }\end{array}$ & NA & $0(0)$ & NA & NA & $2(40.0)$ & NA & $5(17.22)$ \\
\hline \multicolumn{8}{|l|}{$\begin{array}{l}\text { Cause of poor final } \\
\text { visual acuity }\end{array}$} \\
\hline Amblyopia & $6(11.5)$ & $1(16.7)$ & $1(11.2)$ & $9(100)$ & $0(0)$ & NA & $5(26.32)$ \\
\hline Corneal opacity & $4(7.7)$ & $1(16.7)$ & $3(33.2)$ & $0(0)$ & $1(100)$ & NA & $10(52.63)$ \\
\hline High astigmatism & $0(0)$ & $1(16.7)$ & $0(0)$ & $0(0)$ & $0(0)$ & NA & $0(0.00)$ \\
\hline Secondary glaucoma & $0(0)$ & $0(0)$ & $1(11.2)$ & $0(0)$ & $0(0)$ & NA & $2(10.53)$ \\
\hline Retinal detachment & $0(0)$ & $0(0)$ & $0(0)$ & $0(0)$ & $0(0)$ & NA & $0(0.00)$ \\
\hline Macular scar & $0(0)$ & $2(33.2)$ & $1(11.2)$ & $0(0)$ & $0(0)$ & NA & $1(5.26)$ \\
\hline $\begin{array}{l}\text { Traumatic optic } \\
\text { neuropathy }\end{array}$ & $0(0)$ & $0(0)$ & $0(0)$ & $0(0)$ & $0(0)$ & NA & $1(5.26)$ \\
\hline Others & $1(1.9)$ & $1(16.7)$ & $3(33.2)$ & $0(0)$ & $0(0)$ & NA & $0(0)$ \\
\hline
\end{tabular}

${ }^{*}$ Data is presented as mean (range). ${ }^{\dagger}$ Calculated based on total number of injured eyes. ${ }^{\ddagger}$ Calculated based on total number of injured eyes with poor final visual acuity. NA: not available

and Lukaris reported equal involvement of both genders in Pakistani children with traumatic cataract. ${ }^{(15)}$

Our study recruited children with traumatic cataract aged less than 17 years. A majority of our patients were aged at least seven years, with only $17.24 \%$ of patients below six years of age. These findings paralleled those of earlier studies from other Asian countries. ${ }^{(4,12,20)}$ Children older than seven years tend to be more actively involved in various activities, primarily sports and recreation, be it in the home, school, park or sports centre. These children may thus be more vulnerable to injuries than younger children - this is a finding mirrored in our suburban community as well.

A majority of our patients had penetrating ocular injuries. The most common cause of injury was organic foreign body $(24.14 \%)$, particularly wooden sticks, tree branches and sharp thorns. The source of injury was closely related to their daily activities, including during play or handling of such objects at home or in their immediate environment. In a recent study from rural India, Gogate et al similarly reported that traumatic cataract in children were most commonly caused by wooden sticks $(28.0 \%){ }^{(4)}$ 
Johar et al also found that organic foreign body injuries were the most common $(25.0 \%)$ source of injury in their series. ${ }^{(10)}$ However, Kamlesh and Dadeya reported that injuries related to cricket balls and bow and arrows were the most common in their paediatric population. ${ }^{(9)}$ Other researchers were found to have not evaluated analogous variables in their studies. ${ }^{(6-8,11-13,17,20)}$

In some studies, a final visual acuity of $6 / 12$ and better has been reported in $50 \%-80 \%$ of patients, ${ }^{(6,7,9,11,15,20)}$ in contrast to $34.48 \%$ in our cohort. Our findings are similar to Kumar et al's study conducted in Nepalese children with traumatic cataract, which reported only $21.1 \%$ of patients with a final visual acuity of $6 / 12$ and better. ${ }^{(17)}$ In some studies, ${ }^{(6,7,9,11,15,20)}$ amblyopia has been reported as a major cause of poor outcome in the study population.

In our study, $65.52 \%$ of children with traumatic cataract had a final best corrected visual acuity (BCVA) of worse than 6/12, with BCVA of $6 / 60$ or worse being noted in $24.14 \%$ of patients. Over two-thirds of our patients had sustained injuries to the anterior segment structures, and only $17.22 \%$ of patients had involvement of the anterior and posterior segments. The main causes of poor visual acuity were significant corneal opacity and amblyopia. These findings suggest that in order to improve the final visual acuity of children with traumatic eye injuries, more aggressive management and intervention are warranted.

Noncompliance with amblyopia therapy, financial constraints, refusal of penetrating keratoplasty, loss to follow-up and low levels of parental education were some of the obstacles commonly encountered in our patients (data not shown). These findings indicate a clear need for a multidisciplinary team approach when dealing with paediatric patients presenting with traumatic cataract. Such a team should involve paediatric ophthalmologists, cornea and anterior segment experts, welfare officers, educational officers, schoolteachers and social workers.

To conclude, only one-third of our patients with traumatic cataract had satisfactory visual outcome following treatment. Corneal opacity and amblyopia were the main causes of poor visual outcome. Most of the penetrating ocular injuries, which mainly affected boys in our suburban cohort, were preventable. Thus, health awareness programmes that emphasise appropriate strategies should target not only children and their parents, but also other stakeholders such as teachers, school administrators, nongovernmental organisations and policy makers, so as to limit such preventable injuries in the paediatric population. Additionally, continuous and persistent health education via mass media campaigns, the internet and schools should be given greater priority. These educational programmes should not only highlight possible activities or tools that may cause injury to the eyes while in school or at home, but also emphasise the prevention of such injuries. It is also important to provide parents with proper guidance and surveillance so that eye injuries that occur in the home can be limited or prevented. Finally, hospitals should adopt aggressive rehabilitation strategies and postoperative management in paediatric patients presenting with traumatic cataract.

\section{REFERENCES}

1. Maida JM, Mathers K, Alley CL. Pediatric ophthalmology in the developing world. Curr Opin Ophthalmol 2008; 19:403-8.

2. Gilbert C, Foster A. Childhood blindness in the context of VISION 2020-the right to sight. Bull World Health Organ 2001; 79:227-32.

3. Gilbert C, Muhit M. Eye conditions and blindness in children: priorities for research, programs, and policy with a focus on childhood cataract. Indian J Ophthalmol 2012; 60:451-5.

4. Gogate P, Sahasrabudhe M, Shah M, Patil S, Kulkarni A. Causes, epidemiology, and long-term outcome of traumatic cataracts in children in rural India. Indian J Ophthalmol 2012; 60:481-6.

5. Shah MA, Shah SM, Appleware AH, et al. Visual outcome of traumatic cataract in pediatric age group. Eur J Ophthalmol 2012; 22:956-63.

6. Ram J, Verma N, Gupta N, Chaudhary M. Effect of penetrating and blunt ocular trauma on the outcome of traumatic cataract in children in northern India. J Trauma Acute Care Surg 2012; 73:726-30.

7. Shah MA, Shah SM, Applewar A, et al. OcularTrauma Score: a useful predictor of visual outcome at six weeks in patients with traumatic cataract. Ophthalmology 2012; 119:1336-41.

8. Khandekar R, Sudhan A, Jain BK, Shrivastav K, Sachan R. Pediatric cataract and surgery outcomes in Central India: a hospital based study. Indian J Med Sci 2007; 61:15-22.

9. Kamlesh, Dadeya SS. Management of paediatric traumatic cataract by epilenticular intraocular lens implantation: longterm visual results and postoperative complications. Eye (Lond) 2004; 18:126-30.

10. Johar SR, Savalia NK, Vasavada AR, Gupta PD. Epidemiology based etiological study of paediatric cataracts in western India. Indian J Med Sci 2004; 58:115-21.

11. Brar GS, Ram J, Pandav SS, et al. Postoperative complications and visual results in uniocular pediatric traumatic cataract. Ophthalmic Surg Lasers 2001; 32:233-8.

12. Eckstein M, Vijayalakshmi P, Killedar M, Gilbert C, Foster A. Use of intraocular lenses in children with traumatic cataract in South India. Br J Ophthalmol 1998; 82:911-5.

13. Krishnamachary M, Rathi V, Gupta S. Management of traumatic cataract in children. J Cataract Refract Surg 1997; 23 (Suppl 1):681-7.

14. Gupta AK, Grover AK, Gurha N. Traumatic cataract surgery with intraocular lens implantation in children. J Pediatr Ophthalmol Strabismus 1992; 29:73-8.

15. Cheema RA, Lukaris AD. Visual recovery in unilateral traumatic pediatric cataracts treated with posterior chamber intraocular lens and anterior vitrectomy in Pakistan. Int Ophthalmol 1999; 23:85-9.

16. Memon MN, Narsani AK, Nizamani NB. Visual outcome of unilateral traumatic cataract. J Coll Physicians Surg Pak 2012; 22:497-500.

17. Kumar S, Panda A, Badhu BP, Das H. Safety of primary intraocular lens insertion in unilateral childhood traumatic cataract. JNMA J Nepal Med Assoc 2008; 47:179-85.

18. Adhikari S, Badhu BP, Bhatta NK, et al. Etiology and clinical profile of pediatric cataract in a tertiary care center of Eastern Nepal. JNMA J Nepal Med Assoc 2007; 46:94-8.

19. Wilson ME, Hennig A, Trivedi RH, Thomas BJ, Singh SK. Clinical characteristics and early postoperative outcomes of pediatric cataract surgery with IOL implantation from Lahan, Nepal. J Pediatr Ophthalmol Strabismus 2011; 48:286-91.

20. Hyun DW, Lee TG, Cho SW. Unilateral scleral fixation of posterior chamber intraocular lenses in pediatric complicated traumatic cataract. Korean J Ophthalmol 2009; 23:148-52. 